\title{
AN ENVIRONMENT FOR PHYSICAL GEOGRAPHY TEACHING
}

\author{
P. L. BRUSILOVSKY 1 and T. B. GORSKAYA-BELOVA2 \\ ICSTI, Kuusinen Strasse 21b, Moscow-125252 and 2School 243, Oktyabrsky pereulok 11, \\ Moscow, U.S.S.R.
}

\begin{abstract}
Using computers in teaching will have the best effect only when we seriously revise our approach to education itself. In this paper we suggest a possible computer approach to learning geography, based on modelling. To verify this approach we have developed a computer-based unit for the physical geography course which included an intelligent learning environment and which is described in this paper. We tried to use the capabilities of modern hardware (graphics, colour, sound), a modern user interface (windows, menus, icons) and experience of artificial intelligence (AI) applied to education.
\end{abstract}

\section{INTRODUCTION}

Geography was one of the first domains where AI methods were applied for educational purposes [1-3]. The idea of modelling as a universal approach to studying the complex interrelations within the subject became popular long ago in such knowledge domains as maths, physics, and economics. Following Davydov [4], four main characteristics of models are important from a pedagogical point of view.

Models are a means of cognition

Models are representative of the original object which are more appropriate for learning about that object in some way

Models retain the main characteristics of the original

Models are specific to each original object

Taking these characteristics of models into account, the process of modelling can be regarded as a movement from complex, byzantine reality to a model in which reality is deliberately simplified, but with the most significant relations and processes emphasized. The process of dismodelling (from model to reality) allows new insight, enabling the learner to penetrate deeper into the nature of reality.

We consider modelling to be the main method for acquiring knowledge. Dealing with a model, the student learns about it element by element. Gradually, the model becomes constrictive as its limits are appreciated, leading to demands for a more sophisticated model, and so on. Moving from model to model, students absorb the "architecture" of science. The goal is to organize this movement intellectually. Thus the entire course must be assembled as an expanding system of interacting models. Within a modelling approach the computer plays the role of an educational laboratory for investigating the world. This approach is quite well developed now in geography education, where it is regarded as one of the four main approaches to using the computer [5].

Traditionally, the notion of modelling or simulation is related to building mathematical or quantitative models of any process or situation. This tradition originates from the field of physics, and quantitative models are used successfully in all the subdomains of physics. Unfortunately, geography seems to be not quite as appropriate a field for quantitative modelling. As David Unwin writes [5, p. 29]:

"Surprisingly, since a very large amount of courseware making use of simulation techniques has been developed for use in primary and secondary school geography, it seems to be received wisdom that real world systems of interest to geographers in higher education are too complex to be modelled in any useful way for CAL".

As a result, the use of modelling techniques in CAL has concentrated on the obviously "quantitative" areas such as climatology or population demography. One of the possible solutions 
System: Choose the geographic position of your island

Student: <puts the point on the computer map>

System: Decide the structure of the ocean bed in the island location

Student: Continental rise (platform )

System: Decide the type of the Earth's crust

Student: Oceanic

System: Decide the origin of the island

Student: Continental

System: Decide the tectonic structure of the island

Student: Platform

System: Decide the relief of the island

Student: Low mountains

System: Decide the climate of the island

Student: Check <top level menu item>

System: <verifies the student's options> The type of the Earth's crust is oceanic - an error!

If the structure of the ocean bed in the island location is a continental rise ( platform ), then

the type of the Earth's crust is continental. The relief of the island is low mountains - an

error! If the tectonic structure of the island is a platform, then the relief of the island is a

plain.

Fig. 1. The simplest dialogue within the test-kind script. All comment are in ( ) brackets.

to this problem is the use of qualitative (vs quantitative) models in education [6]. This approach is quite well developed now in the field of medical education. Two examples of the use of qualitative models in the field of geography are the well-known systems Meteorology Tutor [2] and Why [3]. Instead of mathematical formulas, knowledge about simulated processes or situations is represented in qualitative models in the form of transition networks [2], scripts [3] or rules [6]. Thus qualitative modelling approach leads us into the field of artificial intelligence and expert systems.

\section{The structure of the learning environment}

The learning environment ISLAND* is for 13-14 yr old students taking a course in the physical geography of oceans and continents. It is the practical result of our studying the problem of modelling with the aid of computers. The pedagogical goal of the environment is to make a transference from the isolated and simple notions of physical geography to the computer modelling of their essential relations in a natural geographical complex.

The computer environment presents several related systems (scripts) realized on an IBM-compatible PC. Working with one of these systems, students find themselves on an island, the position of which can be chosen (depending on the script) either by the student, the system, or the teacher on the map displayed on the screen. Then, knowing the position, the student must decide the natural characteristics of the island: its origin, tectonic structure, climate, the type of crust, soil, flora and fauna. The system enables the student to choose the island in the north part of the Atlantic ocean, and to determine all its natural components, which depend on the position, and to verify the answers. The main abilities of the system can be demonstrated on the example of simplest "test" script (Fig. 1). At the start, the system gives to the student a computer map, where the island's position is marked. With each subsequent question the system offers a menu of possible answers, from which the student makes a selection. The actions of the system are not predetermined, as in traditional CAI systems. For any island position and any of the natural components chosen, the system can verify and comment on all the student's answers. Such capabilities are provided by expert knowledge of the natural complex regularities in it. The knowledge base consists of the rules representing the different natural complex relations. These rules are offered in the IF-THEN form

*The first research script of an ISLAND environment was designed and tested during the summer International Computer School in 1989 in 1989 in Dubna. The authors were joined by psychologist Dr Vadim Khoziev (Moscow University) and Slovakian, German, Bulgarian and Russian schoolboys. All the languages of the test subjects, and English, were supported by the system. The "test" script was written by Moscow University student M. Zyryanov in 1990. It is being used in practice during geography lessons at Moscow School 243. 
IF the structure of the ocean bed is a continental rise,

THEN the type of the Earth's crust is continental,

AND the tectonic structure of the island is a platform.

IF the type of the Earth's crust is continental,

THEN the origin of the island is continental.

IF the tectonic structure of the island is a platform,

THEN the relief of the island is a plain.

Fig. 2. The rules from the ISLAND knowledge base that are relevant to the dialogue in Fig. 1.

(Fig. 2). There are about 60 rules, obtained from several experts in the field of physical geography. In addition, the system has a simple inference machine which can apply the rules to the chosen options, put them into logic chains, and make inferences from the data. The knowledge base and inference machine form a simple expert system, which is the heart of the ISLAND environment. The knowledge in the ISLAND environment can be used in two main regimes: demonstrative and control. In the demonstrative regime, the system can give examples of both forward and backward inference: a student or teaching inputs the climate and the system shows the relevant animals (consequence); and vice versa if the relief is known to be flat, information about its origin may be requested (the reason). In the control regime the system can verify whether or not students are right in their choice of the natural components, the characteristics of the given island. To obtain it, the system solves the same problem comparing its own answers with the student's step by step. With such a verification technique, the system can not only evaluate the student's answer as right or wrong, but also check whether the logical inference was right and even determine what lack of knowledge caused the student's current mistake. It is the student's knowledge of the determinancy principle in the island natural complex structure which is tested as well as the ability to think logically using this knowledge. In spite of having all the rules stored in the knowledge base in a special internal format suitable for processing, the system can generate inferences, information about errors and explanations in natural language (Fig. 1). All the natural language messages may be generated in any of the several languages (Russian, English etc.) provided by the system. For introducing a new language we only have to form vocabulary information files for this language.

\section{Student interface to the ISLAND environment}

Many of the facilities of a graphical user interface are used, including colour and sound. The choice of geographic position of the island can be made by students themselves with the aid of a screen computer map of the northern part of the Atlantic ocean. The current location is marked on the map with a graphic marker which can be moved over the map using the arrow keys to any desired position. To select the proper value of each of the island components, iconic and text menus are used. Each possible value of the natural complex components is provided with a different icon. Movement along the list is by means of the arrow keys. Icons can be used to form a so-called report screen, which is the "instant look-up" feature of the system. A smaller map shows the island's position and one icon for each component. If the value of a component has already been selected by the student, then the corresponding icon appears, and for the remaining components question marks are displayed. The report screen provides the student with visual information on progress. It shows visually the mistakes made by crossing out the icons of incorrect selections. In demonstration mode, the icon, is supplied with a text string underneath giving the name of the corresponding parameter value, e.g. "Low mountains", "High mountains". In test mode all icons are textless-and the selection of the name of the icon is one of the student's tasks (this is a requirement of the teachers who use the system).

\section{Dialogue scripts}

The environment also enables us to build various teaching scripts as separate systems for various educational targets. At the present time two scripts have been built "research" and "test". In the research script the student leads. Having noted the position of the island, other components may 
be fixed in any order, or the report screen may be requested to verify the choice, or a choice may be changed and checked again. The research script gives a student an environment for independent work and experiment, which is becoming more and more popular for the educational systems. This script can also be used by a tutor when explaining or revising the material. The test script is aimed to control and estimate the students knowledge. Here the system leads. It first asks the student to choose the position of an island and then select from the menus the values of all the remaining eight components. Finally the system checks up the choice, displays the errors on the report screen, and generates statements about the errors together with explanations and gives a mark.

\section{Classroom test of ISLAND}

Experiments with the ISLAND test script were made in two ways: in a paper-based exercise and with the computer in control. The aims of this experiment were: first, to determine the level of the students' accomplishment concerning the idea of the unity of nature; second, to evaluate the effectiveness of computer control; third, to compare the results of the paper exercise and computer control.

In the first stage, the students were given questions of various kinds and of increasing complexity.

(1) Explain the peculiarities of a given natural environment, e.g. explain what the value of a component means "in reality"

(2) Determine the geographic position of the given natural environment, i.e. where on the map could an island have this climate, flora etc.

(3) Determine and describe an absent component in a natural environment, i.e. all but one of the components are known-try to derive the missing value from the other components

(4) Find the mistakes in a description of a natural environment, e.g. tigers in an arctic climate

Four of the eight students tested coped with all tasks, two of them failed the third and fourth types, and two of them only managed the first type. Such a result confirms our supposition that students lack of a full conception of a natural environment, because only those who managed the third and fourth types established the relations between the components in ten deep structure levels.

The same students were given a test script of ISLAND. The students had already had experience with computers, so we can compare their answers with the real knowledge level because the novelty element is excluded. We expected that the results would be poorer compared with the paper control, because of the lack of modelling program experience. But the results with computer control turned out to be higher. Five of those tested, after establishing the component interrelations, created the natural environmental model (which corresponds to solving all the paper tasks). Two of the students failed to determine one component (it corresponded to solving three types of tasks), and one student failed to make a model of a natural environment.

The extended help system raised the chance of weak students to solve the problem, and the three-level help structure enables the failing student to solve the problem in the end, which is impossible with the paper control, where a weak student simply gives up. The advanced students after further experience with the program were able to create a mental model of a natural environment. Thus, the number of students with the complete concept of a natural environment after having worked with the computer program increased from four to seven.

Acknowledgement-The author is grateful for the assistance of Dr David Unwin, Department of Geography, University of Leicester, during the preparation of this paper for publication.

\section{REFERENCES}

1. Carbonell J. R., AI in CAI: an artificial intelligence approach to computer aided instruction. IEEE Trans. Man-Mach. Syst. 11, 190-202 (1970).

2. Brown J. S., Burton R. R. and Zdybel F., A model-driven question-answering system for mixed-initiative computerassisted instruction. IEEE Trans. Syst. Man Cybernet. 3, 248-257 (1973).

3. Stevens A. L. and Collins A., The goal structure of a socratic tutor. In Proc. of the 1977 A nnual A CM Conference, pp. 256-263, Seattle (1977).

4. Davydov V. V., Problems of Developing Education. Pedagogika, Moscow (in Russian) (1986).

5. Unwin D. J., Using computers to help students learn: computer assisted learning in geography. A rea 23.1, 25-34 (1991).

6. Clancey W. J., The role of qualitative models in instruction. In A rtificial Intelligence and Human Learning (Edited by Self J.), pp. 49-68. Chapman \& Hall, London (1988). 